\title{
Determination of Trace Concentration in TMD Detectors using PGAA
}

\author{
I. Tomandl ${ }^{1, a}$, L. Viererbl ${ }^{2}$, P. Kudějová ${ }^{3}$, Z. Lahodová2 ${ }^{2}$, V. Klupák ${ }^{2}$ and M. Fikrle ${ }^{1}$ \\ ${ }^{1}$ Nuclear Physics Institute, 25068 Řež, Czech Republic \\ ${ }^{2}$ Research Centre Řež, 25068 Řež, Czech Republic \\ ${ }^{3}$ Maier-Leibnitz Zentrum, TU München, 85748 Garching, Germany
}

\begin{abstract}
Transmutation detectors could be alternative to the traditional activation detector method for neutron fluence dosimetry at power nuclear reactors. This new method require an isotopically highly-sensitive, nondestructive in sense of compactness as well as isotopic content, precise and standardly used analytical method for trace concentration determination. The capability of Prompt Gamma-ray Activation Analysis (PGAA) for determination of trace concentrations of transmuted stable nuclides in the metallic foils of $\mathrm{Ni}, \mathrm{Au}, \mathrm{Cu}$

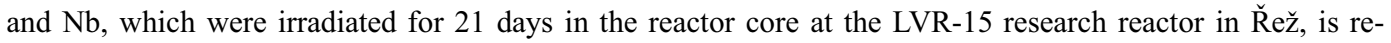
ported. The PGAA measurements of these activation foils were performed at the PGAA facility at ForschungsNeutronenquelle Heinz Maier-Leibnitz (FRMII) in Garching.
\end{abstract}

\section{Introduction}

Reactor dosimetry is an essential part of a nuclear safety assessment. The main goal of reactor dosimetry is the determination of neutron fluence in the various places of a reactor. Neutron fluence is standardly measured by the Neutron Activation Analysis (NAA). To calculate neutron fluence from the activity of the irradiated neutron detectors the irradiation history has to be known. In many cases it is difficult to reconstruct the detailed information on this irradiation history.

The recently suggested transmutation detector method [1] can efficiently work without knowing the irradiation history. Like the NAA method, the transmutation detector (TMD) method uses irradiated neutron detectors. Unlike the NAA method, the TMD method is not based on evaluation of activity of the neutron detector but of trace concentration of transmuted stable (or "nearly stable" - radionuclides with very long half-life) nuclides. These nuclides are produced via common nuclear reactions as $(\mathrm{n}, \gamma)$, $(\mathrm{n}, \alpha),(\mathrm{n}, 2 \mathrm{n})$ and $(\mathrm{n}, \mathrm{p})$. Using the cross sections of these reactions the concentration of these stable nuclides within transmutation detectors can be easily converted into neutron fluence. The information on neutron fluence, which is "written" on TMD, can be "read" with sufficiently sensitive analytical method.

In this work we test the capability of Prompt Gammaray Activation Analysis (PGAA), which is non-destructive and isotopically sensitive, to determine the trace concentration of stable nuclides within the perspective materials for transmutation detectors.

\footnotetext{
a e-mail: tomandl@ujf.cas.cz
}

\section{Experimental procedure}

This experiment was done in two simple steps. The elementary very pure $\mathrm{Ni}, \mathrm{Au}, \mathrm{Cu}, \mathrm{Nb}$ foils were inserted into the vertical channel F6 of the LVR15 research reactor at $\check{R}$ ež and irradiated for 21 days. Then these irradiated samples were analyzed by PGAA method at the high-flux research reactor FRM II in Garching near Munich [2].

TMD samples in form of metallic foils were packed into thin teflon foil and inserted into cold neutron beam at the distance of $33 \mathrm{~cm}$ from the HPGe detector. The weights of these samples are provided in Table 1. They were irradiated by thermal the neutron flux $4 \times 10^{10} \mathrm{~cm}^{-2} \mathrm{~s}^{-1}$ for the $\mathrm{Ni}$ and $\mathrm{Nb}$ foils and $1.5 \times 10^{9} \mathrm{~cm}^{-2} \mathrm{~s}^{-1}$ for the $\mathrm{Cu}$ and $\mathrm{Au}$ foils. The gamma spectra were taken with a standard Compton-suppressed spectrometer consisting of a HPGe with relative efficiency of $60 \%$ and a BGO scintillator surrounding the HPGe detector crystal and connected in anti-coincidence mode. The exampes of the relevant parts of the $(n, \gamma)$ spectra containing PGAA signals from transmuted nuclides is shown in Fig. 1.

\section{Results and comparison with theoretical prediction}

The many prompt and decay $\gamma$ lines originating from transmuted nuclides were identified in the measured PGAA spectra. The most intensive lines of them are summarized in Table 1. The experimental concentrations $C^{P G A A}$ of transmuted nuclides are compared calculated values. Using the known neutron spectrum and cross sections we obtain the predicted values of the concentrations which are in good agreement with the values from PGAA measurements. 
Table 1. Comparison of theoretical and measured concentrations of transmuted nuclides. Note: Expected and PGAA concentrations, $C^{t h}$ and $C^{P G A A}$, respectively, are ratios of the number of transmuted nuclei to the total number of nuclei within target.

\begin{tabular}{|c|c|c|c|c|c|c|c|c|}
\hline $\begin{array}{l}\text { TMD } \\
\text { Element }\end{array}$ & $\begin{array}{l}\text { TMD } \\
\text { Mass } \\
(\mathrm{mg})\end{array}$ & $\begin{array}{l}\text { Counting } \\
\text { time } \\
\text { (s) }\end{array}$ & $\begin{array}{l}\text { Target } \\
\text { nuclide }\end{array}$ & $\begin{array}{l}\text { Transm. } \\
\text { nuclide }\end{array}$ & $\begin{array}{l}\text { Expected } \\
C^{t h} \\
(\mathrm{ppm})\end{array}$ & $\begin{array}{l}\text { PGAA } \\
C^{P G A A} \\
(\mathrm{ppm})\end{array}$ & $\begin{array}{l}\gamma \text {-line } \\
\text { energy } \\
(\mathrm{keV})\end{array}$ & $\begin{array}{l}\text { Counting } \\
\text { sensitivity } \\
\left(\mathrm{mg}^{-1} \mathrm{~s}^{-1}\right)\end{array}$ \\
\hline \multirow[t]{2}{*}{$\mathrm{Ni}$} & \multirow[t]{2}{*}{9.4} & \multirow[t]{2}{*}{28800} & ${ }^{58} \mathrm{Ni}$ & ${ }^{59} \mathrm{Ni}$ & $4.9 \mathrm{E}+02$ & $4.8(3) \mathrm{E}+02$ & 952 & 0.013 \\
\hline & & & ${ }^{62} \mathrm{Ni}$ & ${ }^{63} \mathrm{Ni}$ & $8.3 \mathrm{E}+01$ & $11.0(7) \mathrm{E}+01$ & 1345 & 0.0024 \\
\hline \multirow[t]{3}{*}{$\mathrm{Cu}$} & \multirow[t]{3}{*}{62} & 6330 & ${ }^{63} \mathrm{Cu}$ & ${ }^{64} \mathrm{Ni}$ & $5.0 \mathrm{E}+02$ & $5.5(10) \mathrm{E}+02$ & $1482^{2}$ & \\
\hline & & 49617 & ${ }^{63} \mathrm{Cu}$ & ${ }^{64} \mathrm{Ni}$ & & $6.5(36) \mathrm{E}+02$ & 6035 & 0.0013 \\
\hline & & & ${ }^{63} \mathrm{Cu}$ & ${ }^{64} \mathrm{Zn}$ & $3.3 \mathrm{E}+02$ & $5.9(36) \mathrm{E}+02$ & $7863^{3}$ & 0.0003 \\
\hline \multirow[t]{5}{*}{$\mathrm{Au}$} & \multirow[t]{5}{*}{26} & \multirow[t]{5}{*}{25200} & ${ }^{197} \mathrm{Au}$ & ${ }^{198} \mathrm{Hg}$ & $2.3 \mathrm{E}+04$ & $>0.8(2) \mathrm{E}+04$ & 6206 & 0.0078 \\
\hline & & & ${ }^{197} \mathrm{Au}$ & ${ }^{199} \mathrm{Hg}$ & $1.1 \mathrm{E}+04$ & $1.2(1) \mathrm{E}+04$ & 368 & 101 \\
\hline & & & ${ }^{197} \mathrm{Au}$ & ${ }^{199} \mathrm{Hg}$ & & $0.9(2) \mathrm{E}+04$ & 1570 & 5.8 \\
\hline & & & ${ }^{197} \mathrm{Au}$ & ${ }^{199} \mathrm{Hg}$ & & 1.1(1)E+04 & 5967 & 4.3 \\
\hline & & & ${ }^{197} \mathrm{Au}$ & ${ }^{200} \mathrm{Hg}$ & $0.04 \mathrm{E}+04$ & not assigned & & \\
\hline \multirow[t]{2}{*}{$\mathrm{Nb}$} & \multirow[t]{2}{*}{10.1} & 53553 & ${ }^{93} \mathrm{Nb}$ & ${ }^{94} \mathrm{Nb}$ & $1.9(2) \mathrm{E}+03^{4}$ & $1.7 \mathrm{E}+03^{5}$ & 824 & 0.014 \\
\hline & & 215569 & ${ }^{93} \mathrm{Nb}$ & ${ }^{94} \mathrm{Nb}$ & & $2.4(2) \mathrm{E}+03$ & $766^{2}$ & \\
\hline
\end{tabular}

${ }^{1}$ Counts per seconds divided by TMD weight and normalized to PGAA thermal neutron flux $1 \times 10^{10} \mathrm{~cm}^{-2} \mathrm{~s}^{-1}$

2 Decay $\gamma$-line

${ }^{3}$ Tentatively observed line.

${ }^{4}$ Value calculated from the activity of ${ }^{94} \mathrm{Nb}$.

${ }^{5}$ The rough estimate assuming absolute intensity of $824 \mathrm{keV}$ line from ${ }^{94} \mathrm{Nb}(\mathrm{n}, \gamma){ }^{95} \mathrm{Nb}$ to be 30 per 100 neutron capture.
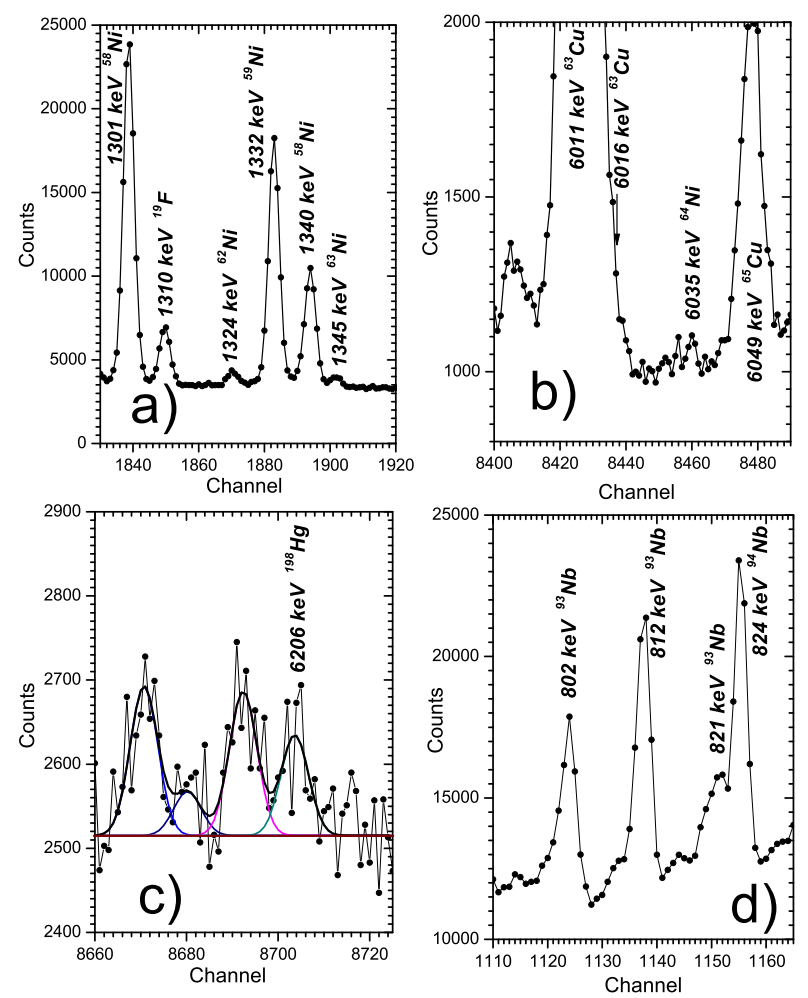

Due to the lack of the partial cross section of $6206 \mathrm{keV}$ line we were able to establish only low limit of the transmuted nuclide ${ }^{198} \mathrm{Hg}$ in the gold foil. Therefore the concentration of ${ }^{198} \mathrm{Hg}$ were checked with X-Ray Fluerescence method (XRF). The XRF concentration of mercury element in gold foil, $3 \pm 0.5 \%$, agrees with the predicted value.

\section{Acknowledgement}

This work has been supported by the Technology Agency of the Czech Republic (projects TA01010237). This work was performed within the scope of research project FRT11/397 of the Ministry of Industry and Trade.

\section{References}

[1] L. Viererbl, Z. Lahodová, V. Klupák, F. Sus, J. Kučera, P. Kus, M. Marek, Nucl. Instr. Meth. A 632, 109 (2011)

[2] L. Canella, P. Kudějová, R. Schulze, A. Türler, J. Jolie Nucl. Instr. Meth. A 636, 108 (2011)

Figure 1. The selected parts of the gamma spectra containing signals from transmuted isotopes. The $\gamma$ lines 1345, 6035, 6206 and $824 \mathrm{keV}$ originating from transmuted isotopes ${ }^{63} \mathrm{Ni},{ }^{64} \mathrm{Ni}$, ${ }^{198} \mathrm{Hg}$ and ${ }^{94} \mathrm{Nb}$, respectively, are exhibited in the graphs a), b), c) and d), respectively. 